\title{
Communicating the luxury dream: The moderating role of brand prominence on the effect of abstract versus concrete language on consumer responses
}

\author{
Cesare Amatulli, Matteo De Angelis ${ }^{* *}$, Carmela Donato ${ }^{\star * *}$
}

\begin{abstract}
The present research considers the effect of using relatively more abstract versus concrete language on consumers' attitudes toward a luxury product and their willingness to buy it. More specifically, the present research investigates the moderating role of brand prominence on the effect of using abstract versus concrete language on consumers' responses. The results of two experiments demonstrate that abstract language leads to higher product attitude and willingness to buy compared to concrete language when brand prominence is low but not when it is high. Implications of this research for theory and practice as well as its limitations are discussed.
\end{abstract}

Keyword: luxury, abstract language, concrete language, brand prominence

First submission: 20/03/2019, accepted: 05/09/2019

\section{Introduction}

Luxury business is one of the most important drivers of growth in many countries (Bain \& Company, 2018a, 2018b). Indeed, decades of steady growth in the global luxury goods market have created an industry worth approximately $€ 915$ billion today, with expectations to reach about $€ 1,260$ billion by 2024 (The Boston Consulting Group, 2018). Two major drivers of

*Associate Professor of Marketing at the University of Bari “Aldo Moro”, Italy. E-mail: cesare.amatulli@uniba.it.

** Associate Professor of Marketing at Luiss University. E-mail: mdeangelis@luiss.it.

*** Lecturer of Marketing at Luiss University. E-mail: donatoc@luiss.it.

Mercati \& Competitività (ISSN 1826-7386, eISSN 1972-4861), 2019, 4 
such growth are the Millennial generation and the Chinese consumers (expected to account for $50 \%$ and $40 \%$ of the luxury market in 2024 , respectively). Concurrently, the growth of the industry has also been driven by experiential luxury, which includes offerings that align more with personal style than with social status (e.g., exclusive hotels, high-end restaurants, wine and cruises, etc.). In fact, BCG estimates that experiential luxury will account for about two thirds of the overall luxury industry economic value by 2022 (https://www.bcg.com/it-it/industries/consumer-products/luxury.aspx).

One of the most important factors behind the success of luxury brands is their ability to allow consumers to dream (e.g., Dubois and Paternault, 1995; Kapferer 1997; Kapferer and Valette-Florence, 2018). While tangible elements of luxury goods certainly contribute to nurturing consumers' dream and aspiration toward luxury items (e.g., Amatulli et al., 2017; Vigneron and Johnson, 1999; 2004), the strategies and tactics employed by luxury brands to communicate the value of their goods to their audience play a crucial role (Amatulli et al., 2018b). In the light of the relevance of communication activities in luxury branding, scholars have dedicated a good deal of attention to examining the impact of different aspects related to luxury goods communication - such as brands' authenticity (Beverland and Luxton, 2005), the use of images versus text (e.g., Amatulli et al., 2018b), the use of celebrities (Erdogan and Drollinger, 2008), the use of social media (Kim and Ko, 2012), the communication message appeal employed (Kwon et al., 2016), and the advertisement content (Massara et al., 2019) - on consumers' emotions, attitudes and behaviors or behavioral intentions.

In this research, we focus on a different, though quite overlooked, relevant dimension of luxury communication, which is the type of language that luxury brands might use to deliver their messages. Specifically, we concentrate on the well-known abstractness/concreteness dimension of language (e.g., Schellekens et al., 2010; Semin and Fiedler, 1988), which refers to the tendency to "use more versus less abstract verbs and predicates when describing experiences and events" (De Angelis et al., 2017, p. 121). As part of this investigation, we build on a study by Hansen and Wänke (2011) that demonstrated that consumers perceive luxury products as more luxurious when they are accompanied by abstract (rather than concrete) descriptions.

In the present research, we investigate the attitudinal and behavioral consequences of using abstract versus concrete language in communication about luxury goods and, more importantly, we delineate an important moderator in the relationship between type of language and consumers' responses, namely consumers' attitude toward the luxury product communi- 
cated and their willingness to buy (hereafter, WTB) it. Specifically, we investigate brand prominence, defined as "the extent to which a product has visible markings that help ensure observers recognize the brand" (Han et al., 2010 , p. 15), which has been shown to be particularly influential on consumers' intention to purchase luxury brands (Cheah et al., 2015; Pino et al., 2019; Shao et al., 2019). In particular, we expect that abstract (vs. concrete) language will increase consumers' attitudes and WTB the luxury product marketed especially when the luxury product is characterized by low (vs. high) brand prominence.

We test this prediction in two experimental studies. Specifically, Study 1 tests the moderating role of brand prominence on the effect of language abstractness on consumer responses, while Study 2 shows that the effect of language abstractness and brand prominence on consumers' attitude towards the luxury product is mediated by consumers' perceptions about that product's luxuriousness.

Overall, our research presents interesting implications for both theory and practice. Regarding the former, the present study investigates the conditions under which the type of language used in luxury brands' communication might produce marketing consequences (e.g., influencing consumers' WTB a luxury product).

In particular, the present research investigates the moderating role of brand prominence that is of paramount importance in luxury consumption research (e.g., Han et al., 2010). In hypothesizing this moderation effect, we strive to illuminate the mechanism linking language type to consumers' approach to luxury goods communication. As regards managerial implications, our study offers interesting suggestions to luxury managers engaged in designing communication strategies. Particularly, it highlights the importance of considering a relevant brand characteristic such as brand prominence when deciding about what type of language to use in communication messages.

In the next section we review the literature on abstract and concrete language and brand prominence. Then, we present our hypotheses, and subsequently our methodology and results. Finally, we discuss the theoretical and practical implications of our work along with its limitations and directions for future research. 


\section{Theoretical Background}

\subsection{Abstract versus concrete language in luxury brands' communica- tion}

Previous luxury research studies have indicated that the "dream formula" (Dubois and Paternault, 1995) needs to be sustained by the appropriate communication strategies (e.g., Fionda and Moore, 2009). In this research, we analyze one relevant aspect of such strategies that we believe to be an important driver of luxury brands' ability to fulfill consumers' desire to dream: the type of language used to convey messages about luxury goods. According to the Linguistic Category Model (hereafter, LCM; Semin and Fiedler, $1988 ; 1991)$, it is possible to categorize a message on the basis of its degree of abstractness versus concreteness. Language abstractness refers to the extent to which people use more abstract (versus concrete) verbs and predicates when describing a specific episode. Maass et al. (1989) identified four levels of language abstractness/concreteness: the first level-i.e., the most concrete one - refers to the use of descriptive action verbs, which allow people to define observable behaviors (i.e., to caress somebody); the second level refers to the use of interpretive action verbs, which allow people to both describe and interpret behaviors (i.e., to take care of somebody); the third level includes state verbs, which refer to the unobservable psychological state of a subject (i.e., to love somebody); finally, the fourth level - i.e., the most abstract one - refers to the use of adjectives, which allow people to generalize the behavior to a trait level (i.e., being tender).

In marketing literature there are several studies that applied the LCM to the word-of-mouth context (e.g., De Angelis et al., 2017; Kronrod and Danziger, 2013; Moore, 2015; Schellekens et al., 2010) converging on the idea that abstract language used in peer-to-peer conversations leads to a higher product attitude and willingness to buy.

Notably, also the literature on luxury brands' communication has ventured into the domain of LCM. In fact, Hansen and Wänke (2011) investigated the linguistic cues that make consumers perceive a product as more versus less luxurious, underlying that consumers perceive products described through abstract language as more luxurious than those described through concrete language. The authors attribute this result to the psychological distance that intrinsically characterizes luxury. Luxury products, in fact, can be afforded only by a relatively small portion of customers, and therefore signal high social distance between those customers and other customers who can- 
not have access to luxury goods (e.g., Miyazaki et al., 2005). The psychological distance that many consumers perceive between themselves and luxury brands is linked, in turn, to people's construal-level representations. Specifically, construal-level theory (hereafter CLT, Trope and Liberman, 2000; 2010) posits that objects that are perceived as psychologically distant (e.g., from a temporal or spatial point of view) tend to be construed more abstractly than those perceived as psychologically proximal. While certainly interesting and thought-provoking, the positive relationship between abstract language and product perceived luxuriousness underlined by Hansen and Wänke (2011) does not consider the marketing effectiveness of the use of abstract language in luxury goods communication.

Moreover, in a recent study on luxury brands' print advertising, Massara et al. (2019) investigated the effect of advertising language abstractness joint with the effect of advertising style (whereby they distinguished between product-based and lifestyle-building advertising) on consumers' willingness to pay, with construal level acting as mediator. Results of this study demonstrated that advertising style moderates the relationship between advertising language and construal level, and thereby willingness to pay, such that "lower construal levels were triggered by concrete language, worked best with product-centered advertising, and positively affected WTP. In contrast, higher construal levels were triggered by abstract language, worked best with lifestyle advertising, and negatively affected WTP" (p. 6).

While previous work has certainly had the merit to shed light on the role of language abstractness used in luxury brands' communication on consumers' responses, offering also evidence for the existence of boundary conditions for this effect (Massara et al., 2019), much remains to be studied about factors that might change the relative effectiveness of abstract versus concrete language in luxury brands' communication. Through the present research, we contribute to advancing this knowledge by focusing on the role of a key feature of luxury products, such as brand prominence.

\subsection{Abstract versus concrete language and luxury brand prominence}

Luxury goods are typically characterized by a good deal of variance in terms of the product design, which reflects the variance in consumers' approaches to luxury purchase and consumption (Han et al., 2010). In particular, luxury market shows that there is much variance in the way luxury brands approach to brand prominence (Cheah et al., 2015; Han et al., 2010; Nunes et al., 2011). To illustrate, while Bottega Veneta is known for using a "no 
logo" strategy, whereby the logo is typically located inside the product, and this it is not prominent at all (Han et al., 2010), brands such as Gucci or Louis Vuitton typically use visible logos which make their products quite easily recognizable to the other people. These examples speak to the idea that the use of brand prominence is a tactical decision that reflects luxury brands' targeting strategy. In that sense the demand for luxury goods seems to split into two markets: one looking for a broader range of more subtle, experiential luxuries based on individual style (internalized luxury) and one looking for goods that can be worn and used to signal status (externalized luxury) (e.g., Amatulli and Guido, 2012; Amatulli et al., 2015; Amatulli et al., 2018a; Eastman and Eastman, 2015). Customers with an internalized luxury approach buy luxury items mainly to abide by their personal style codes and satisfy their tastes (Amatulli et al., 2015; Han et al., 2010), whereas customers with an externalized luxury approach buy luxury items mainly to signal their status and prestige to people in their social contexts (Dubois and Duquesne, 1993; Han et al., 2010; Nueno and Quelch, 1998; Wiedmann et al., 2009). Luxury brands are well aware about the existence of a macro segment of customers who look for a relatively more conspicuous luxury consumption and a macro segment of customers who look for a relatively more discreet luxury consumption (e.g., Kapferer, 2010; Shao et al., 2019); therefore, one relevant factor that mark the difference between such two macro segments of luxury customers might be the way each of them sees brand prominence. Indeed, as stated by Han et al. (2010), brand prominence "clarifies how the relative conspicuousness of a brand's mark or logo reflects different signaling intentions of the owner" (p. 16). Consequently, luxury brands' decision to manufacture products characterized by higher or lower brand prominence witnesses their decision to target one or the other customer segment.

In particular, the presence of luxury goods characterized by high brand prominence seems to be particularly attractive for consumers aiming to signal their status (i.e., externalized luxury consumers), whereas the presence of luxury goods characterized by low brand prominence seems to be more attractive for consumers looking for luxury products that fit with their individual style (i.e., internalized luxury consumers).

Indeed, internalized luxury consumers are typically in-the-know, and thus they neither passively follow what luxury brands dictate to the market nor they need detailed information about the product. Instead, this segment of consumers exhibits relatively high levels of autonomy and freedom in the selection and evaluation of luxury products, assessing goods for what they represent to themselves rather than to others (e.g. Amatulli and Guido, 2012). In short, internalized consumers perceive luxury as an opportunity to create 
their own style, and thus want enough freedom to interpret luxury brands' communication messages in a personal way. Previous research on the effect of abstract versus concrete language in non-luxury contexts has shown that abstract language allows consumers to engage in a mental imagery elaboration process through which they can assign their own meanings to the messages received, and this results in positive consumers' responses to communication messages (De Angelis et al., 2017).

As a consequence of this theorizing, we propose that brand prominence (categorized into high versus low) may moderate the effectiveness of using abstract versus concrete language in luxury brands' communication. In particular, we predict that the higher effectiveness of abstract versus concrete language is more likely to manifest when brand prominence is low rather than when it is high. More specifically, we hypothesize that the use of abstract language leads to higher product attitudes and WTB the luxury product compared to the use of concrete language in the case of low brand prominence, while such a difference is less likely to be observed in the case of a high brand prominence. Of importance, we hypothesize that such a differential effect of abstract versus concrete language for low rather than high brand prominence occurs both as a direct effect of language abstractness and brand prominence $\left(\mathrm{H}_{1}\right)$ on WTB and through the effect of such two factors on product perceived luxuriousness $\left(\mathrm{H}_{2}\right)$. Formally, we hypothesize that:

$H_{1}$ : Brand prominence moderates the effect of language abstractness on consumers' WTB the luxury product. Specifically, the greater effect of using abstract versus concrete language on consumers' WTB is more likely to occur when brand prominence is low rather than when it is high.

$\mathrm{H}_{2}:$ Product perceived luxuriousness mediates the interaction effect of language abstractness and brand prominence on consumers' attitudes.

\section{Methodology}

Below, we present two experimental studies designed to test our hypotheses. Through Study 1, we aim to investigate whether the use of abstract (vs. concrete) language increases consumers' WTB the luxury brand especially in the case of low brand prominence $\left(\mathrm{H}_{1}\right)$. Through Study 2, we aim to demonstrate that the joint effect of language type and brand prominence on consumers attitudes is mediated by perceived brand luxuriousness $\left(\mathrm{H}_{2}\right)$. For both stud- 
ies we used real luxury brands (i.e., Gucci and Prada) referred to a unisex accessory (i.e., a wallet) that is relatively accessible to customers. The use of accessories as test products in our experiments is motivated by the fact that accessories, and in particular small leather goods, cover a large share of luxury purchasing, and are therefore highly relevant for merchandising strategies of luxury brands (Bain \& Company, 2018c). Moreover, accessories are considered the "ideal" category for an online purchase in luxury (Bain \& Company, 2018c) and they allow to fulfill consumers need for self-expression, "as the same accessory can be used by consumers in several settings, complementing multiple pieces of apparel" (Chattalas and Shukla, 2015, p. 47).

\subsection{Study 1}

Study 1 sought to test the moderating effect formalized in $\mathrm{H}_{1}$, which claims that an increase in WTB caused by the use of abstract versus concrete language is more likely to manifest for luxury products characterized by low (vs. high) brand prominence. Therefore, this study involved manipulating both the type of language and the brand prominence.

For Study 1, we first pretested our stimuli - two descriptions (one abstract, one concrete) of a wallet marketed by a real luxury brand (Gucci) and posted on Facebook by that brand (see Appendix 1). The goal of the pretest was to ensure the effectiveness of our language abstractness manipulation.

Pretest 1 . Sixty-nine participants ( 28 females, $M_{\text {age }}=33.73, S D_{\text {age }}=10.97$ ), recruited online among the Facebook contacts of one of the authors, were randomly assigned to one of two conditions within a two-cell between-subjects questionnaire that manipulated the type of language (abstract vs. concrete) used to describe the Gucci wallet. Therefore, we used a convenience sample, whereby we administered our questionnaire to those people with a good expertise about luxury and fashion accessories. Each participant randomly evaluated, on a seven-point scale ( $1=$ very concrete, 7 = very abstract $)$, one of the two wallet descriptions. As expected, the results of the pretest revealed that the abstract language description was perceived as significantly more abstract than the concrete language description $\left(M_{\text {abstract }}=4.48, S D=1.93 ; M_{\text {concrete }}=2.78\right.$, $S D=1.78 ; t(67)=3.82, p<.001)$.

Pretest 2. Next, we conducted a second pretest to assess the perceived brand prominence of two versions of the Gucci wallet. To this end, we recruited 59 
participants ( 32 females, $M_{\text {age }}=33.81, S D_{\text {age }}=11.43$ ) among the Facebook contacts of one of the authors, and randomly assigned them to one of two conditions within a two-cell between-subjects questionnaire that manipulated the prominence of the brand logo (high vs. low) on the wallet. Participants recruited for Pretest 1 were not recruited for Pretest 2 and, similar to Pretest 1 , were selected based on their expertise about luxury and fashion accessories. Using a sevenpoint scale $(1=$ not at all visible, $7=$ very visible $)$, each participant randomly evaluated one of two pictures of the same wallet (the picture featured either a big or small Gucci logo; see Appendix 2). The results showed a significant difference in terms of the perceived brand prominence between the two pictures $\left(\mathrm{M}_{\text {high prominence }}=6.34, S D=1.04: \mathrm{M}_{\text {low prominence }}=3.83, S D=1.66 ; F(1,57)=47.88\right.$, $p<.001)$. We thus proceeded to use the pretested manipulations for the main study.

\subsubsection{Design and procedure}

We recruited 148 participants ( 88 females, $M_{\text {age }}=31.73 ; S D_{\text {age }}=12.34$ ), among the Facebook contacts of a confederate, using the same recruiting criterion as in Pretest 1 and Pretest 2. We randomly assigned participants to one of four conditions within a four-cell between-subjects experiment that manipulated the type of language (abstract vs. concrete) and the brand prominence (low vs. high). Participants first read that they had to evaluate a message posted on Facebook wherein a luxury brand described and presented its new wallet. Depending on the condition, participants were randomly assigned to one of the four pretested experimental scenarios: the picture of a Gucci wallet characterized by high (vs. low) brand prominence and described using abstract (vs. concrete) language. Our dependent variable, WTB the Gucci wallet, was measured through Dodds et al.'s, (1991) three-item scale (i.e., "I would buy this product"; "I could consider buying this product"; "The probability of buying this product is high"), which respondents answered on seven-point Likert scales $(1=$ strongly disagree, $7=$ strongly agree). We averaged the three items to form an overall WTB mean score $(\alpha=.86)$. Finally, participants answered demographic questions. 


\subsubsection{Results and discussion}

A two-way ANOVA on the WTB score revealed that the main effect of language type was not significant $\left(M_{\text {abstract }}=3.91, S D=1.65 ; M_{\text {concrete }}=3.65\right.$, $S D=1.96 ; F(1,146)=.82 ; n s)$, whereas the main effect of brand prominence was significant $\left(\mathrm{M}_{\text {low prominence }}=3.47, S D=1.98 ; \mathrm{M}_{\text {high prominence }}=4.08, S D=1.58\right.$; $F(1,146)=4.36 ; p=.04)$. More importantly, the interaction between language abstractness and brand prominence had a significant effect on WTB $(F(2,144)$ $=7.36, p<.01)$. Planned contrasts showed that WTB associated with abstract language was higher than WTB associated with concrete language when brand prominence was low $\left(M_{\text {abstract }}=4.34, S D=1.79\right.$ vs. $M_{\text {concrete }}=2.96, S D=1.91$, $F(1,144)=6.54, p=.012)$, whereas such a difference in WTB disappeared when brand prominence was high $\left(M_{\text {abstract }}=3.81, \mathrm{SD}=1.32\right.$ vs. $M_{\text {concrete }}=4.00$, $\mathrm{SD}=1.95, F(1,144)=1.63, n s)$. Overall, these findings support $\mathrm{H}_{1}$, demonstrating that the use of abstract language to describe luxury products increases consumers' WTB only when such products are characterized by low brand prominence (see fig. 1).

Figure 1 - Consumers' WTB a luxury Gucci wallet as a function of abstract (vs. concrete) language and high (vs. low) brand prominence

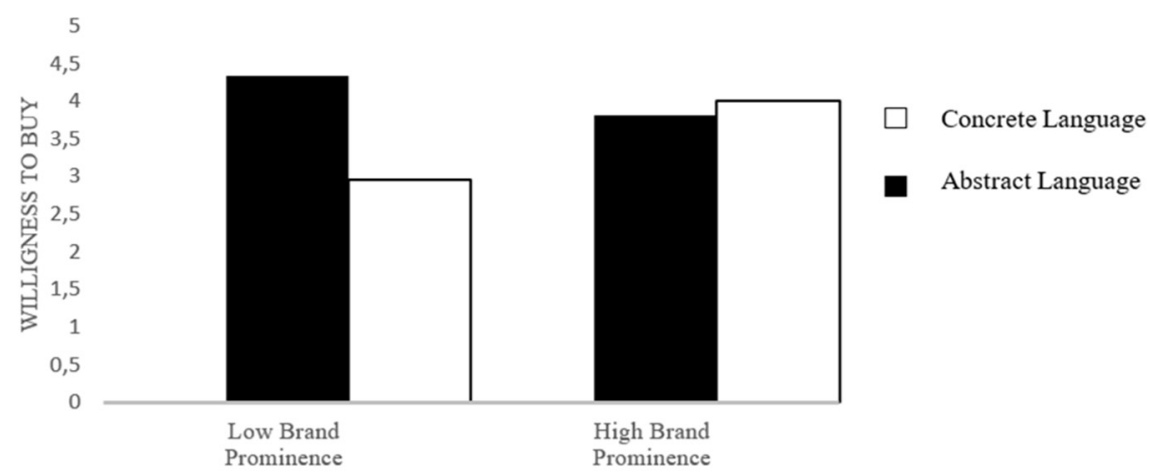

\subsection{Study 2}

Study 2 aimed to test both the mediating and moderating effects formalized in $\mathrm{H}_{2}$ - that is, the mediating role of product perceived luxuriousness alongside the moderating role of brand prominence. Compared to Study 1, which focused on the visibility (high vs. low) of the brand logo, Study 2 uses 
a stronger manipulation of brand prominence by focusing on either the presence or absence of the brand logo (see Appendix 2). This operationalization of brand prominence reflects real product strategies adopted by some luxury brands (e.g., Bottega Veneta).

Pretest 3. As in Study 1 we firstly pretested the effectiveness of the language manipulation with a sample of 63 online respondents ( 27 females, $M_{\text {age }}=36.39$, $S D_{\text {Age }}=11.26$ ) recruited online from an online pool of paid respondents (i.e., Amazon Mechanical Turk). The description used for the pretest was identical to the one used in the main study, except that the former explicitly referred to the product as fictitious (brand "X"). The participants were asked to evaluate the abstractness of the product description on a seven-point scale $(1=$ very concrete, $7=$ very abstract). Then, following the procedure used by Semin and Fiedler (1988; 1991), we asked respondents to rate the language used in terms of its ability to describe the product (i.e., "To what extent was the message describing the wallet able to describe the product itself?" $1=$ not at all, $7=$ very much) and render the product evaluable (i.e., "To what extent did the message describing the wallet allow you to evaluate the characteristics of the product itself?" $1=$ not at all, $7=$ very much). The results revealed, as expected, a significant difference in terms of the perceived language abstractness $\left(\mathrm{M}_{\mathrm{abstract}}=4.78, \mathrm{SD}=1.74\right.$; $\left.\mathrm{M}_{\text {concrete }}=3.23, S D=1.52 ; F(1,61)=14.27, p<.001\right)$. The description characterized by abstract language was also perceived as significantly less able to describe the product $\left(\mathrm{M}_{\mathrm{abstract}}=3.78, S D=1.64 ; \mathrm{M}_{\text {concrete }}=4.97, S D=1.76\right.$; $F(1,61)=7.66, p<.001)$ or render the product evaluable $\left(\mathrm{M}_{\mathrm{abstract}}=3.53\right.$, $\left.S D=1.93 ; \mathrm{M}_{\text {concrete }}=4.65, \mathrm{SD}=1.53 ; F(1,61)=6.37, p=.01\right)$ than the one characterized by concrete language.

\subsubsection{Design and procedure}

One hundred and thirty-eight participants (70 females, $M_{\text {age }}=39.28$; $S D_{\text {age }}=12.31$ ), recruited from an online pool of paid respondents (i.e., Amazon Mechanical Turk), were randomly assigned to one of four conditions within a four-cell, between-subjects experiment in which we manipulated the type of language (abstract vs. concrete) and the prominence of the brand logo (present vs. absent) on the product. Similar to Study 1, we considered a real luxury brand (i.e., Prada) and used one of its wallets as the product.

Participants were initially informed that they would read a small description of a Prada wallet and then answer some questions. In reality, they were randomly assigned to one of the four experimental conditions: the picture of 
a Prada wallet with (vs. without) the brand logo and described using a pretested product description characterized by the use of abstract (vs. concrete) language (see Appendix 1). Then participants indicated the extent to which they perceived the Prada product as a luxurious wallet $(1=$ not at all, $7=$ very much). We then measured respondents' attitude toward the Prada wallet through a five-item scale adapted from Spears and Singh (2004) (i.e., "The wallet I saw is good," "My attitude toward the wallet that I saw is positive", "I react favorably to the wallet", "I like the wallet", "I find the wallet that I saw appealing"), which respondents answered on seven-point Likert scales $(1=$ strongly disagree, $7=$ strongly agree; $\alpha=.96)$. Immediately after, the questionnaire presented a manipulation check question aimed at measuring the perceived abstractedness of the product description (i.e., "On the scale below please indicate extent to which you think the message describing the Prada wallet was": 1 = very concrete; 7 = very abstract). Finally, participants answered demographic questions and were compensated.

\subsubsection{Results and discussion}

In order to test our manipulation, we first performed a one-way ANOVA using the perceived abstractness of the wallet description as the dependent variable. The results indicated that participants in the abstract language condition perceived the description as significantly more abstract than participants in the concrete language condition $\left(M_{\text {abstract }}=3.90, S D=1.60 ; M_{\text {concrete }}=2.68\right.$, $S D=1.29 ; F(1,136)=24.21 ; p<.001)$, thus confirming the success of our manipulation. Then, in order to test the predicted moderation mediation, we estimated Model 7 of the PROCESS macro (Hayes, 2013), considering language type as the independent variable (coded as concrete $=0$, abstract $=1$ ), brand prominence (coded as absent $=0$, present $=1$ ) as the moderator, product perceived luxuriousness as the mediator, and the average score of product attitude as the dependent variable (see fig. 2).

The results showed that both language abstractness $(b=1.50, t=3.98$, $p<.001)$ and brand prominence $(b=1.34, t=3.58, p<.001)$ had a significant effect on product perceived luxuriousness. Importantly, the interaction between them was also significant $(b=-1.13, t=-2.13, p=.03)$. Product perceived luxuriousness, in turn, had a positive effect on product attitude $(b=.34, t=4.51, p<.001)$. The analysis of conditional indirect effects revealed that product perceived luxuriousness significantly mediated the effect of language abstractness on product attitude when brand prominence was absent $(b=.52$, boot $\mathrm{SE}=.19,95 \%$ C.I. $=.21, .97)$, while it did not when 
brand prominence was present $(b=.13$, boot $\mathrm{SE}=.13,95 \%$ C.I. $=-.09, .42)$. Therefore, for low brand prominence abstract language led to higher product attitude compared to concrete language, and this effect is mediated by product perceived luxuriousness; in contrast, for high brand prominence such a mediation effect did not take place. These findings confirm $\mathrm{H}_{2}$ by showing that the effectiveness of language abstractness for luxury brands characterized by low prominence is mediated by the product perceived luxuriousness. Table 1 offers a summary of our empirical results.

Figure 2 - Conceptual model tested in Study 2

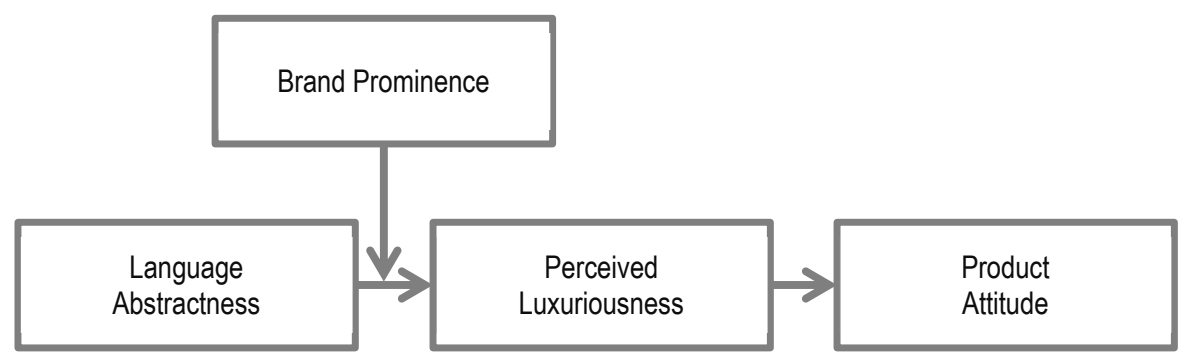

Table 1 - Empirical results summary

\begin{tabular}{|c|c|c|c|}
\hline \multicolumn{4}{|c|}{ Study1 } \\
\hline DV & $\begin{array}{l}\text { Language } \\
F(1,146) \\
=.82 ; n s\end{array}$ & $\begin{array}{l}\text { Brand Prominence } \\
F(1,146)=4.36 \\
\quad p=.04\end{array}$ & $\begin{array}{c}\text { Language*Brand Prominence } \\
F(2,144)=7.36, p<.01\end{array}$ \\
\hline $\begin{array}{c}\text { WTB } \\
\text { (Dodds et al., 1991) }\end{array}$ & $\begin{array}{c}M_{\text {abstract }}=3.91 \\
S D=1.65 \\
M_{\text {concrete }}=3.65 \\
S D=1.96\end{array}$ & $\begin{array}{c}\text { Mlow prom }=3.47 \\
S D=1.98 \\
\text { Mhigh pro }=4.08 \\
S D=1.58\end{array}$ & $\begin{array}{l}\text { LOW BRAND PROMINENCE } \rightarrow \\
M_{\text {abstract }}=4.34, M_{\text {concrete }}=2.96, \\
F(1,144)=6.54, p=.012 \\
\text { HIGH BRAND PROMINENCE } \\
M_{\text {abstract }}=3.81, S D=1.32 \text { vs. } M_{\text {con- }} \\
\text { crete }=4.00, S D=1.95, F(1,144) \\
=1.63, n s\end{array}$ \\
\hline \multicolumn{4}{|c|}{ Study 2} \\
\hline \multicolumn{4}{|c|}{$\begin{array}{l}\text { IV: Language }(0=\text { concrete, } 1=\text { abstract } \\
\text { Moderator: Brand Prominence }(0=\text { absent, } 1=\text { present }) \\
\text { Mediator: Perceived Luxuriousness } \\
\text { DV: Product Attitude (Spears and Singh, 2004) }\end{array}$} \\
\hline \multicolumn{4}{|c|}{ Mediation moderation test } \\
\hline
\end{tabular}

103 


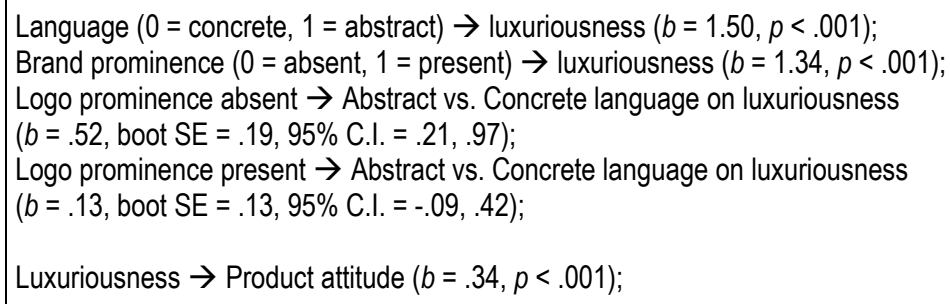

\section{Conclusions}

Today's luxury business is characterized by two relevant and converging consumption trends. Globally, experiential luxury is becoming more important than traditional personal luxury. As a consequence, luxury companies that have typically focused on personal luxury are now extending their strategies and brands to experiential luxury. Such a trend may stem directly from consumers gradually transitioning from an externalized to an internalized approach to luxury - that is, eschewing prestigious products for the sake of signaling social status and instead consuming such products to satisfy their individual style.

In this evolving scenario, luxury companies are increasingly more reliant on communication strategies and tactics to fulfil consumers' desire to dream. Therefore, it is important to understand which communication strategies and tactics are particularly effective at this aim, and under what conditions. Our research sheds light on one specific dimension of luxury brands' communication: namely, the type of language (abstract vs. concrete) that luxury brands may use in order to convey their messages to consumers. In particular, we built on a study by Hansen and Wänke (2011) that demonstrated that abstract descriptions of luxury products make consumers perceive those products and their brand as more luxurious than concrete descriptions. In this vein, our research proposes that the differential effectiveness of abstract versus concrete language is crucially affected by luxury goods' brand prominence. Indeed, we found that abstract language is more effective at increasing consumers' attitudes and WTB when luxury products are characterized by low rather than high brand prominence.

From a theoretical standpoint, our research offers two relevant contributions. First, we extend the findings of Hansen and Wänke (2011) by testing the marketing effects that result from using abstract versus concrete language in 
communication about luxury goods. In particular, our results show that abstract language in luxury communication is more effective in increasing consumers' attitude toward the product and their WTB than concrete language. This has been shown to occur both directly and through an increase in product perceived luxuriousness. Second, and perhaps more importantly, we uncover a relevant boundary condition for this effect, such as brand prominence.

Our work also has some practical implications for managers. In particular, our results suggest that luxury managers should design their communication strategies around a clear vision of their target customers. Specifically, we find that the use of relatively more abstract language in luxury brand communication might be particularly effective for products characterized by low brand prominence. Such products, in turn, are typically more appealing for consumers with an internalized rather than an externalized approach to luxury consumption. For this reason, luxury communication managers should work in close collaboration not only with luxury brands' designers and merchandising managers but also with luxury marketing strategists in charge of defining segmentation and targeting policies. Moreover, confirming the positive relationship between abstract language and perceived luxuriousness already found by Hansen and Wänke (2011), our findings have important implications for advertising. When product descriptions are written in an abstract language, the product is perceived as more valuable and exclusive. This result can be beneficial for emerging brands that want to communicate their exclusiveness or simply their high quality, and that therefore can describe their products using an abstract language. Conversely, for those emerging brands that are less pretentious and that want to be perceived as more affordable, the use of concrete language description is more appropriate.

Finally, our research features some limitations that might open fruitful avenues for future studies. For instance, our research involved online experiments, which may be characterized by rigorous manipulations and measures, but do not necessarily confer external validity to the findings. Therefore, scholars could further validate our hypotheses by developing field experiments where consumers are presented with real advertisements in physical shopping contexts. Second, we focused on one possible boundary condition for the effect of language abstractness on consumer responses to luxury brands' communication messages. Future studies could certainly expand our investigation into the conditions in which abstract versus concrete language could benefit more luxury brands' communication. For instance, building on the study of Massara et al. (2019), future work could verify if our results hold in the case of a lifestyle-building advertising as well as in the case of product-based advertising 
or if in one of such cases the effect of language abstractness and logo prominence might be stronger. Another limitation of our study stems from the dependent variables we used. In this study, we observed the marketing effects of the type of language by focusing on product attitudes and WTB, which are interesting indicators of behavior, but do not represent actual purchase decisions. Therefore, future research could replicate our studies with more practical and realistic dependent variables, such as real product choice. As a final limitation, our experiments all focused on one single product category, such as wallet, which belongs to the category of accessories rather than to that of products and, additionally, is a fairly accessible type of good. Future studies could resolve such a limitation by focusing on different luxury product categories to check whether our results hold.

\section{References}

Amatulli C., De Angelis M., Costabile M. and Guido G. (2017). Sustainable luxury brands: Evidence from research and implications for managers. Berlin: Springer. DOI: 10.1057/978-1-137-60159-9.

Amatulli C., De Angelis M., Korschun D. and Romani S. (2018a). Consumers' perceptions of luxury brands' CSR initiatives: An investigation of the role of status and conspicuous consumption. Journal of Cleaner Production, 194: 277-287. DOI: 10.1016/j.jclepro.2018.05.111.

Amatulli C., De Angelis M., Pichierri M. and Guido G. (2018b). The Importance of Dream in Advertising: Luxury Versus Mass Market. International Journal of Marketing Studies, 10(1): 71. DOI: 10.5539/ijms.v10n1p71.

Amatulli C. and Guido G. (2012). Externalized vs. internalized consumption of luxury goods: propositions and implications for luxury retail marketing. The International Review of Retail, Distribution and Consumer Research, 22(2): 189-207. DOI: 10.1080/09593969.2011.652647.

Amatulli C., Guido G. and Nataraajan R. (2015). Luxury purchasing among older consumers: exploring inferences about cognitive Age, status, and style motivations. Journal of Business Research, 68(9): 1945-1952. DOI: 10.1016/ j.jbusres.2015.01.004.

Bain \& Company (2018a). -- Available at: https://www.bain.com/contentassets/ 8df501b9f8d6442eba00040246c6b4f9/bain_digest_luxury_goods_worldwide_ market_study_fall_winter_2018.pdf.

Bain \& Company (2018b). -- Available at: https://www.bcg.com/d/press/20february 2018-altagamma-true-luxury-global-consumer-insight-184693.

Bain \& Company (2018c). -- Available at: https://altagamma.it/media/source/ WORLDWIDE\%20LUXURY\%20MARKET\%20MONITOR_BAIN.pdf. 
Beverland M. and Luxton S. (2005). Managing integrated marketing communication (IMC) through strategic decoupling: How luxury wine firms retain brand leadership while appearing to be wedded to the past. Journal of Advertising, 34(4): 103-116. DOI: $10.1080 / 00913367.2005 .10639207$.

Chattalas M. and Shukla P. (2015). Impact of value perceptions on luxury purchase intentions: a developed market comparison. Luxury Research Journal, 1(1): 4057. DOI: $10.1504 /$ LRJ.2015.069806.

Cheah I., Phau I., Chong C. and Shimul A.S. (2015). Antecedents and outcomes of brand prominence on willingness to buy luxury brands. Journal of Fashion and Marketing Management: An International Journal, 19(4): 402-415. DOI: $10.1108 / \mathrm{jfmm}-03-2015-0028$.

De Angelis M., Tassiello V., Amatulli C. and Costabile M. (2017). How language abstractness affects service referral persuasiveness. Journal of Business Research, 72: 119-126. DOI: 10.1016/j.jbusres.2016.10.006.

Dodds W.B., Monroe K.B. and Grewal D. (1991). Effects of price, brand, and store information on buyers' product evaluations. Journal of Marketing Research, 307-319. DOI: $10.1177 / 002224379102800305$.

Dubois B. and Duquesne P. (1993). The market for luxury goods: Income versus culture. European Journal of Marketing, 27(1): 35-44. Doi: 10.1108/ 03090569310024530.

Dubois B. and Paternault C. (1995). Observations: Understanding the world of international luxury brands: The "dream formula". Journal of Advertising Research, 35(4): 69-76.

Eastman J.K. and Eastman K.L. (2015). Conceptualizing a model of status consumption theory: An exploration of the antecedents and consequences of the motivation to consume for status. Marketing Management Journal, J. 25(1): 1-15.

Erdogan B.Z. and Drollinger T. (2008). Endorsement practice: How agencies select spokespeople. Journal of Advertising Research, 48(4): 573-582. DOI: $10.2501 / \mathrm{s} 0021849908080549$.

Fionda A.M. and Moore C.M. (2009). The anatomy of the luxury fashion brand. Journal of Brand Management, 16(5-6): 347-363. DOI: 10.1057/bm.2008.45.

Han Y.J., Nunes J.C. and Drèze X. (2010). Signaling status with luxury goods: The role of brand prominence. Journal of Marketing, 74(4): 15-30. DOI: 10.1509/jmkg.74.4.15.

Hansen J. and Wänke M. (2011). The abstractness of luxury. Journal of Economic Psychology, 32(5): 789-796. DOI: 10.1016/j.joep.2011.05.005.

Hayes A.F. (2013). Mediation, moderation, and conditional process analysis. In: Introduction to Mediation, Moderation, and Conditional Process Analysis: A Regression-Based Approach. New York: Guilford Publications (1-20). DOI: 10.1111/jedm.12050.

Kapferer J.N. (1997). Managing luxury brands. Journal of Brand Management, 4(4): 251-259. DOI: $10.1057 / \mathrm{bm} .1997 .4$.

Kapferer J.N. (2010). Luxury after the crisis: Pro logo or no logo. The European Business Review: 42-46.

Kapferer J.N. and Valette-Florence P. (2018). The impact of brand penetration and awareness on luxury brand desirability: A cross country analysis of the relevance 
of the rarity principle. Journal of Business Research, 83: 38-50. DOI: 10.1016/j.jbusres.2017.09.025.

Kim A.J. and Ko E. (2012). Do social media marketing activities enhance customer equity? An empirical study of luxury fashion brand. Journal of Business Research, 65(10): 1480-1486. DOI: 10.1016/j.jbusres.2011.10.014.

Kronrod A. and Danziger S. (2013). "Wii will rock you!" The use and effect of figurative language in consumer reviews of hedonic and utilitarian consumption. Journal of Consumer Research, 40(4): 726-739. DOI: 10.1086/671998.

Kwon J., Seo Y. and Ko D. (2016). Effective luxury-brand advertising: The ES-IF matching (entity - symbolic versus incremental - functional) model. Journal of Advertising, 45(4): 459-71. DOI: 10.1080/00913367.2016.1226995.

Maass A., Salvi D., Arcuri L. and Semin G.R. (1989). Language use in intergroup contexts: The linguistic intergroup bias, Journal of Personality and Social Psychology, 57(6): 981. DOI: 10.1037//0022-3514.57.6.981.

Massara F., Scarpi D. and Porcheddu D. (2019). Can Your Advertisement Go Abstract Without Affecting Willingness to Pay?: Product-Centered versus Lifestyle Content In Luxury Brand Print Advertisements. Journal of Advertising Research. DOI: $10.2501 /$ jar-2019-005.

Moore S.G. (2015). Attitude predictability and helpfulness in online reviews: The role of explained actions and reactions. Journal of Consumer Research, 42(1): 30-44. DOI: 10.1093/jcr/ucv003.

Miyazaki A.D., Grewal D. and Goodstein R.C. (2005). The effect of multiple extrinsic cues on quality perceptions: A matter of consistency. Journal of consumer research, 32(1): 146-153. DOI: 10.1086/429606.

Nueno J.L. and Quelch J.A. (1998). The mass marketing of luxury. Business Horizons, 41(6): 61-61. DOI: 10.1016/s0007-6813(98)90023-4.

Nunes J.C., Drèze X. and Han Y.J. (2011). Conspicuous consumption in a recession: Toning it down or turning it up?. Journal of Consumer Psychology, 21(2): 199205. DOI: $10.1016 /$ j.jcps.2010.11.002.

Pino G., Amatulli C., Peluso A.M., Nataraajan R. and Guido G. (2019). Brand prominence and social status in luxury consumption: A comparison of emerging and mature markets. Journal of Retailing and Consumer Services, 46: 163-172. DOI: 10.1016/j.jretconser.2017.11.006.

Schellekens G.A., Verlegh P.W. and Smidts A. (2010). Language abstraction in word of mouth. Journal of Consumer Research, 37(2): 207-223. DOI: $10.1086 / 651240$.

Semin G.R. and Fiedler K. (1988). The cognitive functions of linguistic categories in describing persons: Social cognition and language. Journal of Personality and Social Psychology, 54(4): 558. DOI: 10.1037/0022-3514.54.4.558.

Semin G.R. and Fiedler K. (1991). The linguistic category model, its bases, applications and range European Review of Social Psychology, 2(1): 1-30. DOI: 10.1080/14792779143000006.

Shao W., Grace D. and Ross M. (2019). Consumer motivation and luxury consumption: Testing moderating effects. Journal of Retailing and Consumer Services, 46: 33-44. DOI: 10.1016/j.jretconser.2018.10.003. 